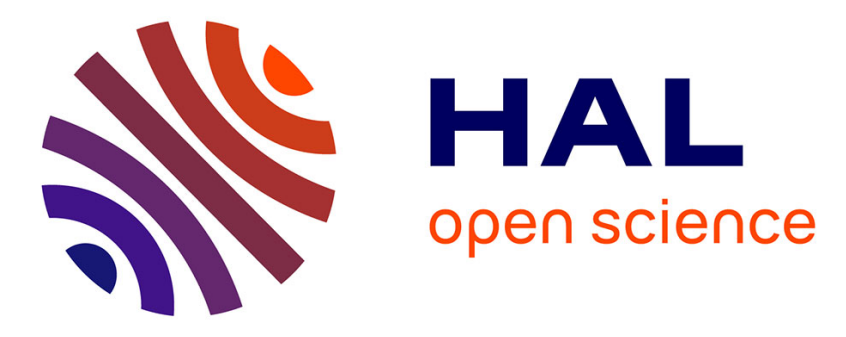

\title{
Resonant grating pulse compression element with $99 \%$ flat top efficiency for high average power femtosecond laser machining
}

\author{
M. Flury, N. Lyndin, R. Fechner, A. Schindler, S. Tonchev, M. Spajer, Y.
}

Ouerdane, N. Destouches, D. Pietroy, S. Reynaud, et al.

\section{To cite this version:}

M. Flury, N. Lyndin, R. Fechner, A. Schindler, S. Tonchev, et al.. Resonant grating pulse compression element with $99 \%$ flat top efficiency for high average power femtosecond laser machining. SPIE Photonics Europe Photon management. Conference No 2, Apr 2006, Strasbourg, France. pp.61871I.161871I.6, 10.1117/12.668374 . hal-00369185

\section{HAL Id: hal-00369185 https://hal.science/hal-00369185}

Submitted on 12 Apr 2021

HAL is a multi-disciplinary open access archive for the deposit and dissemination of scientific research documents, whether they are published or not. The documents may come from teaching and research institutions in France or abroad, or from public or private research centers.
L'archive ouverte pluridisciplinaire HAL, est destinée au dépôt et à la diffusion de documents scientifiques de niveau recherche, publiés ou non, émanant des établissements d'enseignement et de recherche français ou étrangers, des laboratoires publics ou privés. 


\title{
Resonant grating pulse compression element with $99 \%$ flat top efficiency for high average power femtosecond laser machining
}

\author{
Manuel Flury ${ }^{\mathrm{a}}$, Nikolay Lyndin ${ }^{\mathrm{b}}$, Renate Fechner ${ }^{\mathrm{c}}$, Axel Schindler ${ }^{\mathrm{c}}$, Svetlen Tonchev ${ }^{\mathrm{d}}$, Michel \\ Spajer ${ }^{\mathrm{e}}$, Youcef Ouerdane ${ }^{\mathrm{a}}$, Nathalie Destouches ${ }^{\mathrm{a}}$, David Pietroy ${ }^{\mathrm{a}}$, Stéphanie Reynaud ${ }^{\mathrm{a}}$, Olivier \\ Parriaux* ${ }^{\mathrm{a}}$ \\ ${ }^{a}$ Laboratoire Traitement du Signal et de l’Instrumentation, UMR 5516, 18 rue Benoît Lauras, 42000 \\ Saint-Etienne, France; \\ ${ }^{\mathrm{b}}$ Institute of General Physics, Vavilova Str. 38, 117942 Moscow, Russia; \\ c Institute of Surface Modification, IOM, Permoserstr. 15, 04318 Leipzig, Germany; \\ d Institut of the Solid State Physics, Bulgarian Academy of Science, 72 Tzarigradsko Chaussee \\ Blvd, 1784 Sofia, Bulgaria; \\ ${ }^{\text {e }}$ Institut FEMTO-ST, Département LOPMD - UFR Sciences, route de Gray, 25030 Besançon \\ cedex, France.
}

\begin{abstract}
Top hat diffraction efficiency in an all-dielectric $\mathrm{SiO}_{2} / \mathrm{HfO}_{2}$ grating femtosecond pulse compression grating is demonstrated with a close to $100 \%$ flat top over more than $20 \mathrm{~nm}$ around $800 \mathrm{~nm}$ wavelength. New perspectives are open for high average power femtosecond laser machining.
\end{abstract}

Keywords : pulse compression, gratings, multilayers.

\section{INTRODUCTION}

It is known that conventional metallized gratings are not suitable in femtosecond pulse compression stages to be used in a regime of high average power. Heat dissipation leads to a rapid deterioration of the underlying resin corrugation. As early as in the mid nineties all-dielectric reflection gratings demonstrated their capability of achieving larger and close to $100 \%$ efficiency [1] and of sustaining larger flux [2]. Since then, this technology has led to industrial products of impressive size and efficiency [3]. Most achievements and products have so far targeted high energy femtosecond pulses of less than $100 \mathrm{fs}$ duration and low repetition rate at $1054 \mathrm{~nm}$ wavelength.

There is now a need for more industrial applications where the demands are different : the nominal wavelength is that of a Ti:sapphire laser around $800 \mathrm{~nm}$, the pulse duration is significantly above $100 \mathrm{fs}$, and the repetition rate is much larger, in the multi-KHz range. This implies that the damage mechanisms are not so much the electronic discharges in the dielectric layers, but the average power, therefore thermal effects. An important consequence is that the grating can be made in the high index last layer which considerably widens the domain of parameters where $100 \%$ diffraction efficiency can be obtained, and requests much shallower grating depths than in silica : less than $100 \mathrm{~nm}$ in $\mathrm{HfO}_{2}$ or in $\mathrm{Ta}_{2} \mathrm{O}_{5}$ instead of more than $500 \mathrm{~nm}$ in silica for the same grating period. This also implies that the bandwidth of the compression gratings needn't be as wide as in ultrashort pulse applications (20 $\mathrm{nm}$ bandwidth seems to be sufficient).

The main demand on gratings for high average power applications is on the diffraction efficiency. The efficiency of alldielectric gratings can easily reach $100 \%$ theoretically and it is possible to get close to the theoretical maximum indeed [4]. However, the diffraction efficiency spectrum has usually the form of a smooth maximum with the efficiency falling to lower values off maximum. The present contribution reports on a very different diffraction efficiency spectrum exhibiting theoretically a $100 \%$ plateau over a wide spectral range, and on the successful technological and experimental demonstration of this new electromagnetic behaviour. As a comparison, figure 1 shows a typical diffraction efficiency 
spectrum obtained theoretically from a structure comprizing a standard quarter wave reflector at $800 \mathrm{~nm}$ wavelength under $60^{\circ} \mathrm{TE}$ incidence with a $536 \mathrm{~nm}$ grating period defined in a last layer of silica. The incidence and diffraction conditions in this reference example are the same as those considered in the present paper. Most often, the corrugation is made in the last layer of the multilayer which is silica because silica is easy to etch. It is also believed that the flux resistance of silica is larger than that of a high index layer [2].

In this example, the quarter wave multilayer mirror is designed for the incident beam. The considered layer index are those which are usually assumed in a ion plating process. The optimization parameters are the groove depth, its width and the thickness of the unetched silica layer. The objective function in the optimization is the $-1^{\text {st }}$ order diffraction efficiency at $800 \mathrm{~nm}$. It can be seen that under the prescribed conditions the diffraction efficiency is limited to below 80 $\%$ at $800 \mathrm{~nm}$.

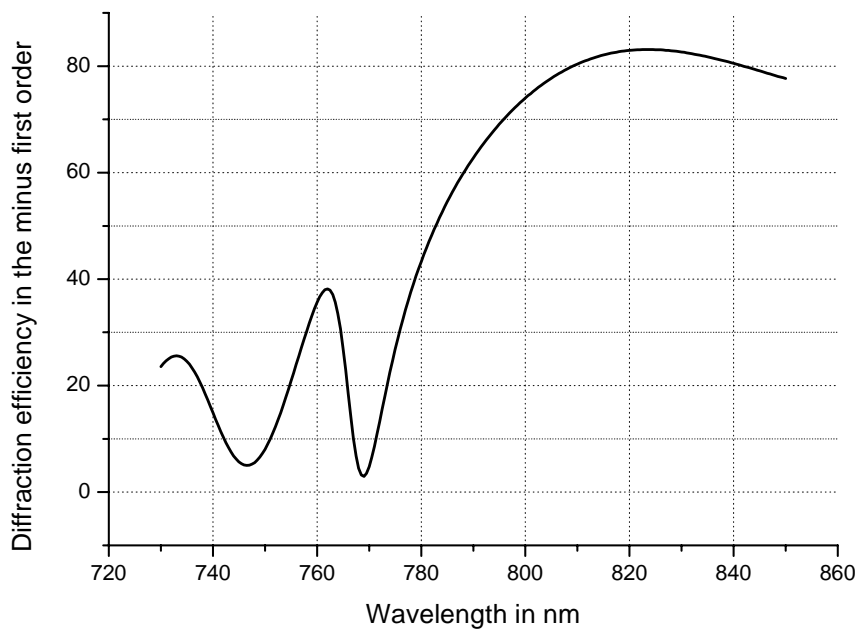

Figure $1:-1^{\text {st }}$ diffraction efficiency spectrum in a standard dielectric mirror based corrugated silica layer with $n\left(\mathrm{SiO}_{2}\right)=$ $1.48, \mathrm{n}\left(\mathrm{HfO}_{2}\right)=2.118$, groove depth $=650 \mathrm{~nm}$, groove width $=342 \mathrm{~nm}$ and $193 \mathrm{~nm}$ unetched silica layer.

\section{DESIGN ASPECTS}

The compression grating described here is composed of a multilayer mirror with a pair of low and high layers on top, the grating being made in the last high index layer of hafnium oxide. It is usually thought [5] that $100 \%$ diffraction efficiency is an effect of constructive interference between the $-1^{\text {st }}$ order directly diffracted by the grating and the $-1^{\text {st }}$ order diffracted down and reflected by the multilayer mirror. The explanation does not account for the modelling results obtained off-Littrow by optimization method. The more physical and correct explanation of high diffraction efficiency is the refractive excitation of a leaky mode of the mirror based pair of layers [6] which enables the cancellation of the $0^{\text {th }}$ reflected order which implies that the power has nowhere else to go but to be $100 \%$ diffracted in the $-1^{\text {st }}$ reflected order. With this vision in mind, it is not only possible and easy to adjust the film thicknesses so that the analytical dispersion equation of a leaky mode is satisfied [7], it is also possible to taylor the dispersion of the multilayer so that the dispersion equation is satisfied over a requested wavelength range.

Figure 2 is an illustration of the electromagnetic mechanism used to achieve $100 \%$ diffraction efficiency. The zero ${ }^{\text {th }}$ order reflection of incident beam (a) onto the mirror based structure consists of two contributions : the Fresnel reflection (c) from the top interface and the reflection from the mirror (g). If the dispersion equation of a leaky mode propagating in the mirror based layer (b) is satisfied, both contributions are real, but they are opposite sign, the contribution of the trapped and re-radiated wave being of large modulus. 


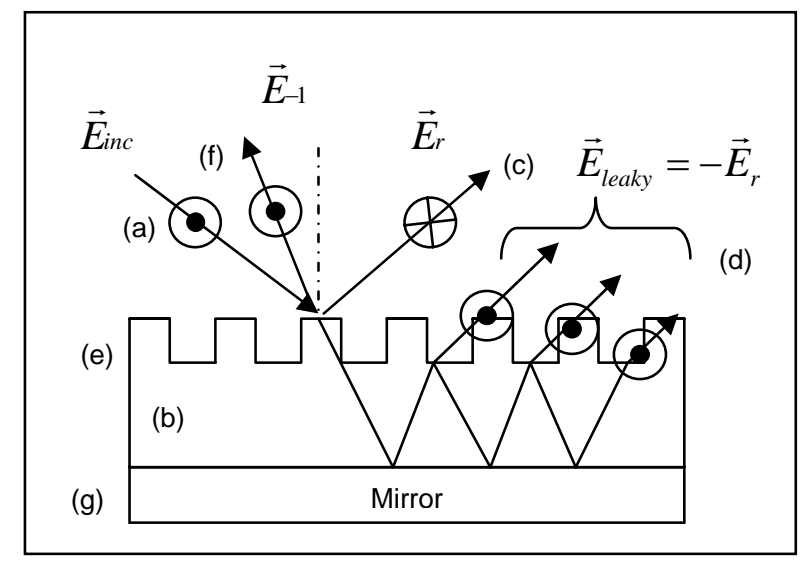

Figure 2 : Leaky mode excitation (d) enabling the cancellation of the $0^{\text {th }}$ reflected order (c).

This very fact gives the unique possibility of balancing the modulus of the two contributions by deteriorating somehow the field accumulation in the leaky mode, this can be achieved by placing a grating at the air - layer interface. The grating not only degrades the field accumulation, thus permitting the nulling of the reflection, it also dictates the direction where the energy mode propagate once the zero ${ }^{\text {th }}$ order reflection has been cancelled out. This mechanism was shown to operate in all $-1^{\text {st }}$ order resonant grating analyzed so far [7]. The theoretical diffraction efficiency spectrum is centered at $800 \mathrm{~nm}$ wavelength with a flat top of $25 \mathrm{~nm}$ width at $100 \%$ efficiency presented in the figure 3 . Such efficiency profile is very attractive for high average power industrial femtosecond lasers.

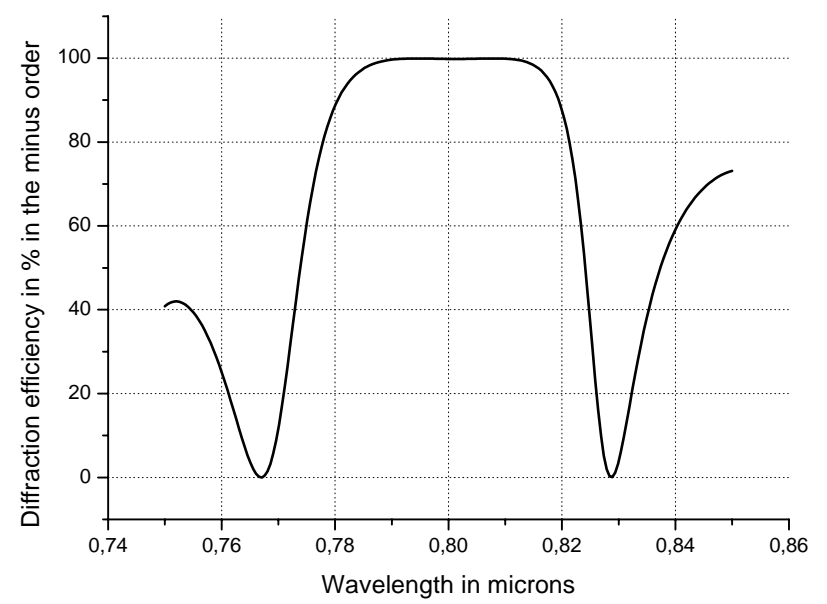

Figure 3 : Theoretical diffraction efficiency versus wavelength in a multidielectric mirror based pair of low and high index layers.

\section{FABRICATION AND CHARACTERIZATION}

The multilayer is made of alternate $\mathrm{SiO}_{2}$ and $\mathrm{HfO}_{2}$ layers on a quartz substrate with an ion plating techniques. The grating was first made in a resist film exposed to an HeCd laser interferogram, then etched down by RIBE. The grating groove profile measured by AFM reveals close to rectangular grooves of $105 \mathrm{~nm}$ depth and about 0.75 line/space ratio which is close to what the optimisation of the structure led to. Figure 4 is the SEM picture of the cleaved edge of the obtained corrugation in the last $\mathrm{HfO}_{2}$ layer by means of reactive ion beam etching. It exhibits a trapeze ridge profile making an angle of $20^{\circ}$ with the normal. 


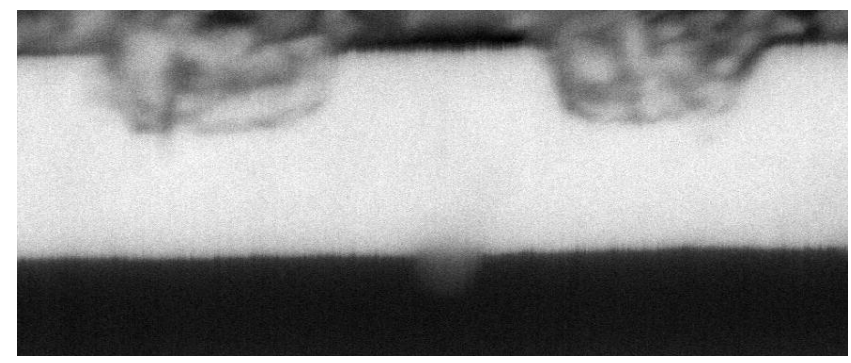

Figure 4 : SEM Picture of the corrugated hafnia layer cross section.

The $0^{\text {th }}$ and $-1^{\text {st }}$ orders diffracted by a fabricated grating are measured by means of the set up sketched in figure 5 . The grating samples have a $50 \mathrm{~mm}$ diameter. The measurement set up comprises different angular stages and a rotation stage. The latter controls the incidence angle of the collimated beam to within $0.02^{\circ}$. The diffraction efficiency is defined as the ratio between the diffracted power and the incident power. The referencing to the incident power was not made real time but sequentially at each wavelength step. The stability of the laser during a wavelength step scan was better than $3 \%$. The power measurement head is a universal optical power system (Melles Griot Model 13 PDC001) with a $67 \mathrm{~mm}$ diameter integrating sphere and silicon detector usuable between 400 and $1100 \mathrm{~nm}$.

The component was illuminated with a tunable titanium doped sapphire laser pumped by argon laser : the tuning range was between $710 \mathrm{~nm}$ to $850 \mathrm{~nm}$ wavelength. The beam polarization is linear and TE. The polarization control was carefully made by means of a polarization maintaining fiber followed by a Wollaston prism. It is of critical importance since the used resonant diffraction effect is highly polarization dependent whereas $0^{\text {th }}$ order reflection below $1 \%$ must be measurable. The perpendicularity between the incidence plane and the grating lines is also critical importance for estimating the device ultimate performance : the two diffraction orders and the incident beam were made coplanar. The wavelength was calibrate to better than 1 nanometer.

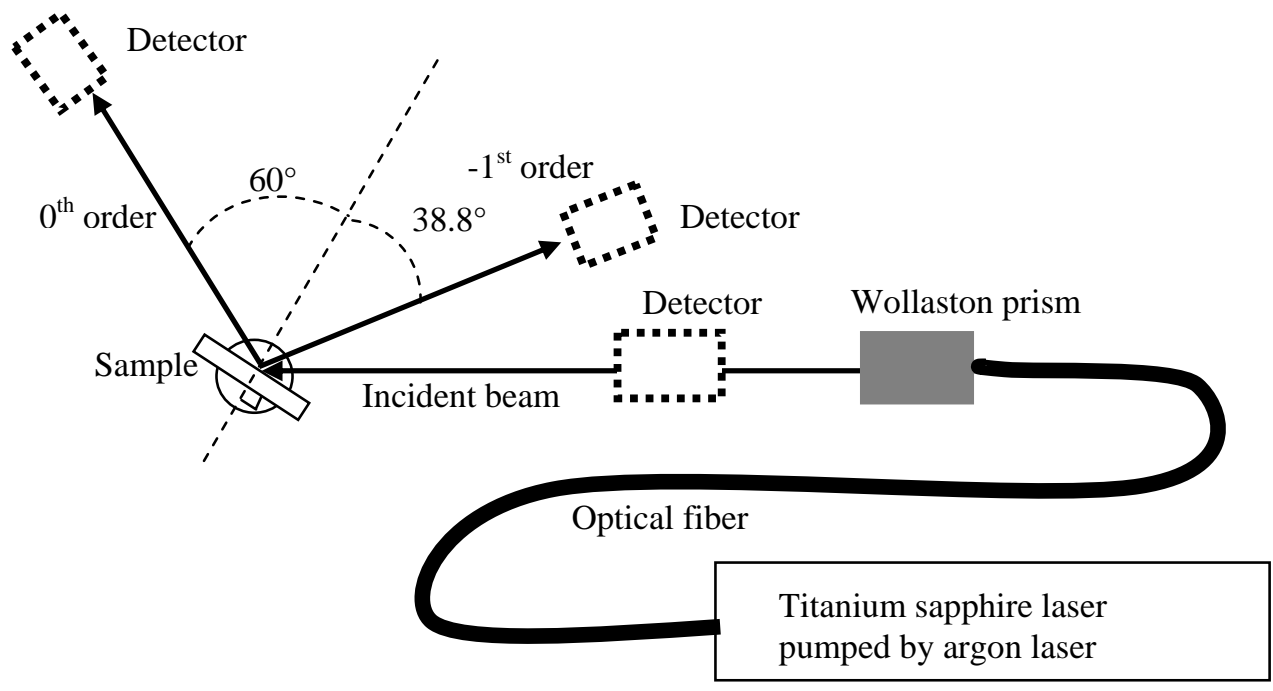

Figure 5 : Sketch of the measurement setup 
The experimental measurement of the $-1^{\text {st }}$ order diffraction efficiency validates the design objective : a flat top diffraction efficiency larger than $97 \%$ over a bandwidth of $20 \mathrm{~nm}$ is obtained. The experimental efficiency curve of figure 6 is slightly shifted to shorter wavelengths which is attributed to some drift in the refractive index of the layers at the multilayer deposition stage.

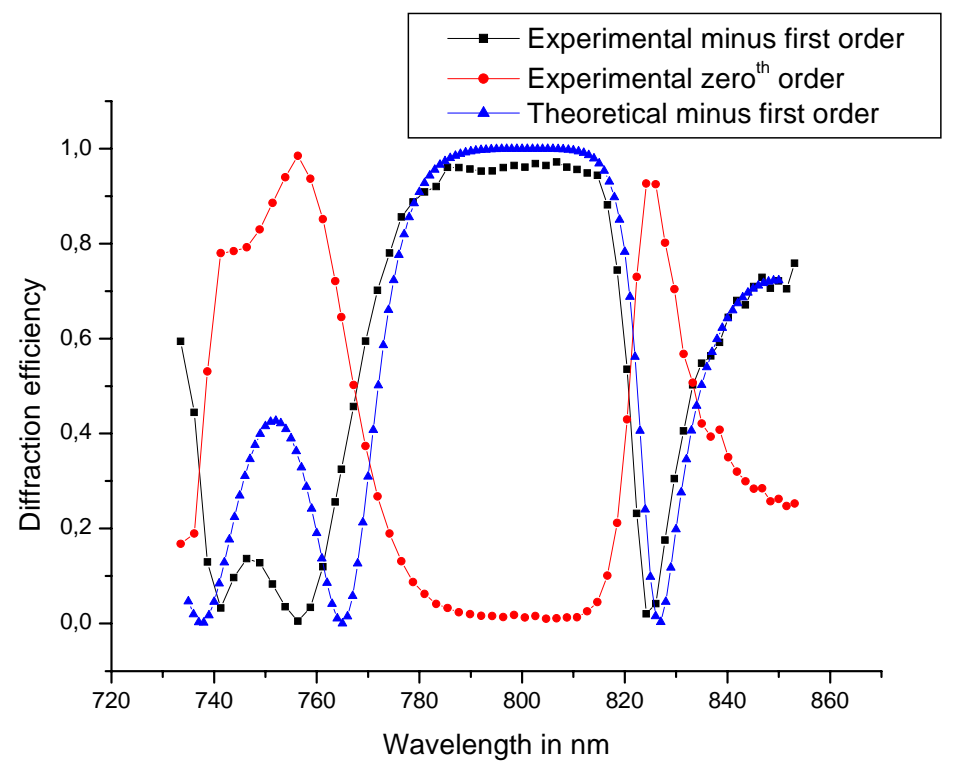

Figure 6 : Theoretical and experimental $-1^{\text {st }}$ order diffraction efficiency and experimental $0^{\text {th }}$ order reflection spectra in a $\mathrm{HfO}_{2} / \mathrm{SiO}_{2}$ multilayer based grating of $536 \mathrm{~nm}$ period under $60^{\circ}$ incidence of the TE polarization.

\section{CONCLUSION}

It was shown that maximum diffraction efficiency of close to $100 \%$ can be kept over a sufficiently wide wavelength range to ensure superior system efficiency in high average power femtosecond machining lasers of pulse duration larger than $100 \mathrm{fs}$.

\section{ACKNOWLEDGEMENT}

The authors of the TSI Laboratory are grateful to the CNRS MRCT FEMTO for its support of this work and the strong incentives and collaborative action of its partners.

\section{REFERENCES}

1. M.D. Perry et al., High-efficiency multilayer dielectric diffraction gratings, Opt. Lett., Vol. 20, 1995, pp. 940-942.

2. J.A. Britten et al., High-efficiency, dielectric multilayer gratings optimized for manufacturability and laser damage threshold, SPIE Vol. 2714, 1996, pp. 511-520.

3. B. Touzet et al., Multilayer dielectric gratings enable more-powerful high-energy lasers, Photonics Spectra, Sept. 2003, pp. 68-75.

4. K. Hehl et al., "High-efficiency dielectric reflection gratings: design, fabrication, and analysis", Appl. Opt., Vol. 38, 1999, pp. 6257-6271. 
5. Lifeng Li, All-dielectric reflection gratings: a study of physical mechanism for achieving high efficiency, Appl. Opt., Vol. 42, 2003, pp. 6255-6260.

6. A.V. Tishchenko, V.A. Sychugov, High grating efficiency by energy accumulation in a leaky mode, Opt. \& Quant. Electron., Vol. 32, 2000, pp. 1027-31.

7. M. Flury et al., Leaky mode resonance condition ensures $100 \%$ diffraction efficiency of mirror based resonant gratings, Proc. Diffractive Optics DO 2005, Warsaw, 3-7 Sept. 2005. 